des scheinbar Begriffenen, speisen sich die Entwicklungen im Sozialen und im

Erkennen. Selbstverständlich schickt sich solches nicht für ein Lehrbuch, das gattungsgemäß das nach- und abprüfbare Wissen kodifiziert. Soziologie als Erkenntnis aber ist tatsächlich dazu angetreten, hinter den Spiegel zu blicken und Horizonte zu überschreiten. In Flaschen abgefüllt und konserviert verliert sich das Aroma. Für die Rechtssoziologie bedeutet das allerdings nicht bloß eine Frage des Geschmacks - es könnte eine der Existenz sein.

\title{
Sibylle Tönnies Eines Nachmittags im Juristischen Seminar
}

Ducken muß man sich, bevor man in die Juristenfabrik hineinkommt. Keine Eingangshalle, sondern ein enger Betonschlauch nimmt einen auf, der zu einem Nadelöhr führt, durch das man schlüpfen muß, bevor man sich in der Welt der juristischen Literatur tummeln darf. Das Nadelöhr besteht aus einer durch Stellwände erreichten Engführung, die wie ein Kleinlabyrinth um einige Ecken führt, herum um einen Glaskasten, in dem ein Kontrolleur den Ein- und Ausgang beobachtet, den Ausgang daraufhin, ob nicht vielleicht ein Baumbach-Hefermehl mitgeführt wird oder ein Schwarz-Kleinknecht, den Eingang daraufhin, ob nicht ein zu diesem Zweck bestimmtes Gefäß hereingetragen wird. Nun, man hat passiert und ist drin, drin in der Fabrikhalle mit unendlichen Regalreihen und unendlichen Tischreihen, an denen mit gebeugten Rücken die Juristen der Zukunft ihre Nasen in die Baumbach-Hefermehls und Schwarz-Kleinknechts stecken. Wenn sie aber aufstehen und zwischen den Regalen flanieren, sind sie keineswegs gebeugt, sondern flotte, frischgeschorene, frischgekämmte, frischgewaschene Yuppies in guten Jeans und Markenpullovern.

Ja, und dazwischen bewegt sich die nicht mehr ganz junge Dame und wundert sich, wie fremd ihr diese Welt geworden ist.

Die nicht mehr ganz junge Dame bin ich natürlich selbst. Nach einigen Stunden Arbeit, einigen Stunden Hin- und Herlaufen zwischen den Bücherreihen und den Räumen, treppauf treppab durch die Etagen verliert sich das Gefühl des Fremdseins. Unten im Magazin riecht es wie vor fünfundzwanzig Jahren schon, als das Juristische Seminar noch in einem anderen Gebäude lag, im Hochhaus 4.-7. Stock, wo ich studiert und Stein-Jonas und Thomas-Putzo kennengelernt habe. Die tausend und abertausend verstaubten Papiere haben ihren Geruch mitgenommen in das neue Betonhaus hinten am Autobahnzubringer. Dieser Geruch, den ich länger kenne als die anderen hier im Gebäude, gibt mir das Gefühl, hier doch nicht so verkehrt zu sein, hier doch auch hinzugehören - in gewisser Weise hier besonders hinzugehören. Nach einigen Stunden bewege ich mich frei in diesen Hallen und fühle mich auch nicht mehr älter als die jungen Leute, spüre im Gegenteil in meinen Bewegungen eine provozierende Jugendkraft, spüre, wie die Unternehmungslust, mit der ich meine Bücher suche, hier fehl am Platz ist, - spüre die Jakobinermütze, die mir am Kopf festgewachsen ist und die jetzt offenbar rot leuchtet.

$\mathrm{Da}$ ist doch noch jemand in diesem Gebäude, der mit dem Staubgeruch umgezogen ist, der mit allen Thomas-Putzos und Baumbach-Hefermehls eingepackt und umgeladen worden ist - Professor X. Er wandelt jovial auf den Gängen, gealtert, aber keineswegs verfallen, im Gegenteil gestrafft und gestärkt, nicht mehr der unsicher- 
listige junge Kerl, sondern ein stattlich-selbstbewußter Mann in den besten Jahren mit nettem kleinen Bäuchlein. Ich gehe einmal an ihm vorbei und fühle mich neugierig gemustert. Ob er mich erkennt oder nur gewohnheitsmäßig eine Frau taxiert, so wie er es sich denn jetzt, nachdem er in seine Professorenwürde fünfundzwanzig Jahre hineinwachsen durfte, erlauben kann? Ich gehe meiner Wege und versinke wieder in die Rechtsphilosophie, die etwas separat ganz oben einen gemütlichen kleinen Raum beherrscht; die alten Bände entfalten die alte Atmosphäre, die gute alte Atmosphäre von Paul Anselm Feuerbach, der das Strafen in die Fesseln des Gesetzes gelegt hat, die gute alte Atmosphäre von Gustav Radbruch, der am Nazi-Unrecht sich den Kopf zerbrochen hat. Alte Nazis stehen natürlich auch in den Reihen, entströmen aber keinen Duft, sind ganz still - die schlimmsten unter ihnen werden wohl noch unten im Magazin sein und dort im sogenannten Giftschrank, an den niemand ran darf. Oder ob dieser nach fünfundzwanzig Jahren freigegeben ist, nachdem die Professoren, die damals den Hitlerstaat verherrlicht und seine Befreiung von Recht und Gesetz gefeiert hatten, nicht mehr unter uns wandeln, nachdem sie ersetzt sind durch die neue Generation ihrer herangewachsenen früheren Assistenten, durch die Herren, die ihnen die Aktentasche trugen und aus der Hand fraßen? Ich brauche ein Zitat aus Ingo Müllers »Furchtbare Juristenж. $\mathrm{Da}$, wo es systematisch hingehörte, steht es nicht. Ich gehe hinunter drei Treppen in den Katalograum; doch, Ingo Müllcr gibt es auch hier in diesem Seminar, mit dessen Büchern er wie ich studiert hat. Das Buch aber ist unten im Magazin und nur auf schriftlichen Antrag erhältlich. Ob es wohl im Giftschrank liegt, zusammen mit der Literatur, gegen die es angeschrieben ist? Es wäre da systematisch richtig: bei den unliebsamen Erinnerungen unter Verschluß. Nein, ganz so gut versteckt ist Ingo nicht, ich kann das Buch bestellen und habe Aussicht, es in einer halben Stunde zu bekommen. Ich will mich wieder an meinen Arbeitsplatz begeben, da begegnet mir abermals der inzwischen herangewachsene Professor X. Er blickt mir wieder so neugierig-quick ins Gesicht, daß ich mich wieder frage, ob er mich erkennt. Es steht ihm gut, daß seine Haare nicht mehr braun, sondern grau sind. Er sieht so offen und freundlich aus. Wenn er mich erkennt, ist mir die Erinnerung peinlich, in der er mich haben muß. Wir waren ein kleines Häufchen aufmüpfiger Studenten, eine linke Studentengruppe im Winter 1968/69, die Basisgruppe Jura, schlimme Gesellen, die das Recht als Instrument der Ausbeuter betrachten lernen wollten und sich zu diesem Zweck an dunklen Abenden an dunklen Orten trafen, nicht im Juristischen Seminar, versteht sich, an dessen einer Säule ein Hinweiszettel mich aber doch zu diesen dunklen Treffen geführt hatte. Wir lasen Karl Marx, Lohnarbeit und Kapital, und ließen uns die Köpfe rauchen von Gebrauchswert und Tauschwert, wir lasen Wiethölter, der das Recht kritisch betrachtete und uns zeigte, als welche Hure es sich erwiesen hatte, der uns aber auch auf Aristoteles und Platon verwies, weshalb wir bei unseren dunklen Treffen auch in die Helle des klassischen Altertums blickten. Kurz und gut - diese Gruppe wollte auch praktisch werden, und das bedeutete: Man wollte verhindern, daß die jugendlichen Erstsemester das Bürgerliche Recht als gottgegeben und richtig auffaßten und dadurch kapitalistisch deformiert wurden, man wollte den Anfängern seine sozio-ökonomische Bedeutung klarmachen, bevor sie in seine Einzelheiten stiegen. Dazu wurde ein Flugblatt verfaßt und zu Beginn der Anfängervorlesung verteilt, man setzte sich unter die Anfänger und wartete Professor $\mathrm{X}$ ab, danals noch jung, braunhaarig und unsicher. Er kam gar nicht dazu, in die Frage von vollmachtloser Stellvertretung einzusteigen, er wurde bombardiert mit Fragen und Statements, denen er zunächst sich bemühte, gewachsen zu sein, bis er eingestand, von diesen sozio-ökonomischen Dingen nicht genügend zu verstehen, Marx nicht zu kennen. Wie er sich dazu berechtigt fühle, die 
Jugend zu bilden, blindes Wissen unters Volk zu streuen, dem Kapital und damit dem Verderben zuzudienen usw. - man ließ nicht locker, man ließ es zu seinen vorbereiteten Ausführungen über vollmachtlose Stellvertretung nicht kommen; er verlor den Kopf und verließ den Saal. Vorlesungen sprengen nannte sich das, ich habe es nur dieses eine Mal mitgemacht, es stellte den Höhepunkt meiner kriminellen Energie dar: Ich war an den bohrenden Fragen beteiligt und hatte das Flugblatt verfaßt, das auf den Gedanken von Eugen Paschukanis beruhte, eines revolutionären Russen, den Stalin umgebracht hatte - was aber in meinen Kreisen versch wiegen wurde und mir erst seit kurzem bekannt ist -, eine Information, die im Giftschrank der Linken verschlossen war.

Nun, jetzt traf ich Professor X wieder, und er blickte mir neugierig-listig ins Gesicht. Ich schämte mich meiner Jugendsünde, der Grobheit und Ungehörigkeit des Vorfalls, seiner Militanz und Destruktivität. Ich ging auf ihn zu, stellte mich dem neugierig-listigen Blick und fragte: »Kennen Sie mich noch? « Nein. Wer sind Sie denn?" "Ich gehörte in der Studentenbewegung zu einer Gruppe, die sich sehr ungezogen benommen hat zu Ihnen. Wir haben Ihre Vorlesung gesprengt.« $\mathrm{Da}$ lachte er hell auf. "Ach ja, damals, ach ja, hahaha, nein, ich kenne Sie nicht mehr. Sind Sie denn immer noch so ungezogen? « Nein, ich bin ganz artig. Und es tut mir leid, daß wir uns damals so schlecht benommen haben. "Ach, das war doch nicht so wild, ja, das waren wilde Zeiten, aber ... na, das ist nun sowieso alles vorbei, mit dem Sozialismus, das war ja alles Unsinn, das hat sich ja jetzt erwiesen, jetzt will ja keiner mehr etwas davon wissen, die müssen jetzt alle einpacken. Hahaha!« Fröhlich-listig bohrt sich sein Blick in mich hinein. Nein, auf dieser Ebene will ich mich nicht verständigen. So will ich meine Jugend nicht verraten. Läßt doch Marquis Posa als letztes an Don Carlos ausrichten: „Sagen Sie ihm, daß er für die Träume seiner Jugend soll Achtung tragen, wenn er ein Mann sein wird! Nun bin ich eine Frau geworden und merke jetzt, unter diesem fröhlichen Blick, daß es da noch etwas festzuhalten gibt, was nicht mit dem Glauben an dialektischen und historischen Materialismus, Diktatur des Proletariats und den demokratischen Zentralismus flöten gegangen ist: die Moral, die moralische Sicht auf die Dinge, der Wunsch, daß es gerecht und friedlich zugehe, besteht immer noch und wehrt sich gegen den zudringlich-verständigungssuchenden Blick.

"Ich gebe zu, daß die sozialistische Ideologie eine ungeeignete Grundlage war für unseren Protest, aber wir brauchten eine geistige Basis, um uns von den alten Nazis abzusetzen. « $\mathrm{Da}$ ist der Blick nicht mehr fröhlich-konsenssuchend. "Wie? Was meinen Sie? Wen meinen Sie? « $\mathrm{Na}$, die ganze Fakultät war doch voller alter Nazis! « Da verengen sich die Augen, und er, den doch die Gnade der späten Geburt trifft, ist offenbar angestochen. „So, alte Nazis? Ja, was meinen Sie denn, hätten Sie damals gemacht? Meinen Sie, Sie hätten damals den Mund aufgemacht? Meinen Sie, Sie hätten Lust gehabt auf den Volksgerichtshof? "Dabei macht er eine wahrhaft furchterregende Geste: Er streicht sich mit der Handkante waagerecht über den $\mathrm{Hals}$, wobei ihm die Augen und Zunge heraustreten. "Meinen Sie, Sie hätten das gewollt - so:« und er wiederholt die Geste. Auf dieser Ebene will und kann ich mich auch nicht verständigen. Hat er Recht? Nein! Es gab nicht nur Opfer des Volksgerichtshofs, sondern auch Täter, und von diesen sprechen wir gerade. "Ich hoffe, ich hätte es gewoltt! « sage ich tapfer und in gerader Haltung, ich fühle mich merkwürdig, ein leichter Schwindel erfaßt mich. "So, das hätten Sie also gewollt! Na gut, aber bei Honecker, was hätten Sie da gemacht? Bauzen, Rummelsburg, hätten Sie dahingewollt? Und...« Er zählt alle Zuchthäuser der DDR auf, und die kleinen Augen leuchten dabei. "Wissen Sie, ich sage immer, der Mensch besteht aus fünf Trieben« - er nimmt seine fünf Finger zuhilfe und zählt, wobei er erst den Daumen 
ergreift. "Liebe!« Er zwinkert mir, jetzt wieder freundlich-listig, zu. »Sie wissen schon, was ich meine. Haha! Zweitens - jetzt ist der Zeigefinger dran. „Geld! Drittens « - jetzt zieht er die Augenbrauen hoch und legt seine Stirn in intelligente Runzeln: "Macht! « Ich werde unruhig und versuche, das Gespräch zu beenden, mich zu entziehen, aber er ist jetzt richtig warm geworden und im Fluß. Ich muß mir die beiden, dem Ring- und kleinen Finger zugeordneten Triebe auch noch anhören, kriege sie aber nicht mehr mit, so unruhig bin ich geworden. Aber jetzt läßt er nicht mehr los. Er sagt das, was er offenbar immer sagt, wenn das Gespräch subtil wird, und da ist er nicht zu bremsen. Jetzt will er mir die Sache an dem chinesischen Bett erklären. "Wissen Sie, ich benutze immer das Beispiel, wie in China das Bett gekauft wird. Das habe ich bestimmt damals auch schon erzählt. Erinnern Sie sich noch? « "Ja natürlich, die Sache mit dem Bett! « Ich gebe vor, mich zu erinnern, so bleibt mir diese Sache erspart. Ich will jetzt Gewalt anwenden und mich körperlich entziehen, da fällt mir noch etwas Wichtiges ein. Jetzt sehe ich ihn fest und listig an: "Sie wollten mir vorhin die Bereitschaft zum Widerstand absprechen. Da will ich Ihnen doch etwas sagen, was Sie vielleicht gar nicht wissen: Ich habe wegen meiner Zugehörigkeit zur Basisgruppe Jura damals ein Berufsverbot erhalten, mußte dieses Land verlassen und bin nur mit Ach und Krach noch untergekommen. "Was wollten Sie denn werden? "Richterin. "Wie haben Sie denn Examen gemacht? «Ich nenne ihm die Note, und er bezeugt Respekt. Daran kann es nicht gelegen haben. Ich erzähle ihm von dem Genossen Heiner, der nicht einmal Referendar werden durfte, dessen Fall das Bundesverfassungsgericht beschäftigt hat in einer inzwischen in der Literatur prominenten Entscheidung. "Und das Böseste, was wir je geplant und getan haben, war das, was wir mit Ihnen gemacht haben!« Jetzt erregt er sich und schüttelt sich. "Aber das war doch gar nichts! Das war doch eine Bagatelle! Ja, das war doch im Grunde ganz interessant! Das war die Zeit damals! Ja, denken Sie bloß nicht, daß ich das dem Verfassungsschutz gemeldet hätte. Nein - ich habe damit nichts zu tun! « Ich dachte das auch bisher nicht, war noch gar nicht auf die Idee gekommen, wußte ich doch, daß wir einen Spitzel in der eigenen Gruppe hatten, den kurzgeschorenen Unglücksknaben Hermann, der uns einmal unter Tränen ein Geständnis machte von einer gutbezahlten Tätigkeit, auf die er nicht verzichten konnte, hatte er doch schon Weib und Kind. Nein, in dem Punkt konnte ich Professor X wieder beruhigen, und er faßte wieder Fuß und kam in seinen Redeschwall. An dem Punkt, an dem er wieder das sagen wollte, was er immer sagte, nicht die Geschichte mit dem chinesischen Bett, sondern die andere Erklärung, die er immer brachte, wenn die Dinge kompliziert zu werden drohten: die Sache mit den fünf Trieben, die man sich an fünf Fingern abzählen kann; an dieser Stelle, als er den ersten Finger ergriff, bevor ich mich mit ihm über die Liebe verständigen mußte, sagte ich mich los: "Jetzt habe ich keine Zeit mehr. Ich muß arbeiten." $\mathrm{Da}$ half ihm nichts mehr, es gab einen Abschied mit Handschlag, man trennte sich, ein Karteischrank war schon zwischen uns, als er sich noch einmal umdrehte und auf mich zukam. "Ach bitte, wie ist doch Ihr Name? « Ich war verdutzt, wenig geneigt, mich auszuweisen, aber: Wer bin ich, daß man meinen Namen nicht wissen darf? Ich nannte ihn, er ließ ihn in sein Gedächtnis sinken und wandte sich mir noch einmal freundlich-jovial zu: "Aber denken Sie nicht, daß ich Sie jetzt dem Verfassungsschutz melde!« Nein, das dachte ich nicht. Aber ich dachte: Ich würde es wieder tun. 